THE WABASH CENTER

JOURNAL on TEACHING

\title{
Inequality, Innovation, and Reform in Higher Education: Challenges of Migration and Aging Populations
}

\author{
Maria Slowey, Hans G. Schuetze, and Tanya Zubrzycki, editors \\ Switzerland: Springer, 2020 (330 pages, ISBN 978-3-030-28226-4, \$109.00)
}

This recent book in the Lifelong Learning Book Series focuses on two underrepresented, yet impactful, groups in the future of higher education: migrants and older students. Employing an intersectional approach, the book engages "the central role that socially engaged higher education might play in addressing these challenges, enhancing lifelong learning opportunities and facilitating more positive outcomes for both individuals and societies"

(3). As a result, its twenty-one chapters are both theoretically and practically oriented; chapters typically analyze case studies for broader principles and future applications. Chapter authors are teachers and scholars of higher education whose work and intellectual interests span the globe.

The book is organized into four parts. In Part I, "New Demographics and Lifelong Learning," the editors supply an introductory chapter that frames migration and aging as global trends requiring a response from higher education. Part II, titled “Contemporary Patterns of Migration and Higher Education: Opportunities for New Lifelong Learners," contains ten chapters centered on access and training for migrant students. The seven chapters in Part III, "Aging Populations and Changing Life Course Patterns: Implications for Higher Education and 'Longlife' Learners," tackle questions related to the educational needs of adults in all life stages. Finally, Part IV, "Reflections and Outlooks," has three chapters that offer a larger view of current trends and projected outcomes.

While scholars of religious studies and theology may find this book's earlier chapters of particular interest, these final chapters are especially valuable for ongoing conversations about the teaching and learning of migrant and aging populations in the discipline. In Chapter 19, “Mobility and Migration: Freedom and Threat?," Pavel Zgaga attends to recent shifts in mobility and migration patterns to offer a timely assessment of the societal and democratic roles of higher education and the European Higher Education Area (EHEA). David Istance takes a similar approach by recognizing shifts in aging in Chapter 20, "Learning, Education, and Active Aging: A Key Policy Agenda for Higher Education." Istance offers several initial considerations for the education and learning of older adults. He proposes wider use of the term "active aging" and invites institutions of higher education to identify themselves as community partners and knowledge providers for this population. The final chapter, "Higher Education in the Twenty-First Century: New Frontiers-Old Barriers," by Han G. Schuetze and Maria Slowey, explores the implications for "lifelong learning" in higher education with particular attention to the usefulness of that category, as well as trends and new developments that will inform future work on the topic.

Relevance, access, and rights are global concerns in higher education; the realities of migration and aging provide higher education with challenges and possibilities for teaching and learning of all students in all stages of life.

276 2021; 2:1 276-276 The Wabash Center Journal on Teaching

This work is licensed under a Creative Commons Attribution-NonCommercial 4.0 International License 